\title{
EDITORIAL
}

\section{Intracranial pressure thresholds in severe traumatic brain injury: we are not sure}

\author{
Prudent clinical practice despite dogma or nihilism \\ Nino Stocchetti ${ }^{1,2^{*}}$ (D, Daniele Poole ${ }^{3}$ and David O. Okonkwo ${ }^{4}$
}

๑ 2018 Springer-Verlag GmbH Germany, part of Springer Nature and ESICM

Intracranial hypertension is a dangerous, sometimes fatal, complication of traumatic brain injury (TBI). Sudden increases in intracranial pressure (ICP) may cause brain herniation; sustained ICP elevations may lower cerebral perfusion pressure and cause diffuse brain ischemia. Substantial agreement exists on the dangers of intracranial hypertension, but when this threat is translated into actual clinical thresholds for treatment, i.e., millimeters of mercury $(\mathrm{mmHg})$, a range of opinions emerges.

Important TBI clinical trials have used varying ICP thresholds for the management of intracranial hypertension. The DECRA trial aggressively randomized patients to decompressive craniectomy with an ICP $>20 \mathrm{mmHg}$ even for a short duration [1]. In contrast, in the more recent RESCUE-ICP trial, patients were eligible for randomization to decompressive craniectomy when their ICP was sustained above $25 \mathrm{mmHg}$ for hours [2].

Daily clinical practice, outside trials, exhibits a degree of consistency. For example, in a survey of 66 European neurotrauma centers, three institutions declared to start treatment for an ICP $>15 \mathrm{mmHg}$, but the overwhelming majority ( $83 \%$ of respondents) used a threshold of $>20 \mathrm{mmHg}$ [3]. This practical orientation (i.e., to treat an $\mathrm{ICP}>20 \mathrm{mmHg}$ ) was incorporated in an international consensus conference which proposed a flexible approach, with ICP $>20-25 \mathrm{mmHg}$ as a viable threshold.
The recommendation was to manage TBI patients by combining the ICP measurement with clinical observation and repeated imaging [4].

The latest American Brain Trauma Foundation (BTF) guidelines for severe TBI update the recommended treatment threshold to $>22 \mathrm{mmHg}$ [5], based on class 2 evidence; this value was promulgated as a level IIB recommendation. The new recommendation is admittedly based on low-quality evidence, and legitimate questions are raised about whether the underlying data properly supports the recommendation. The new guideline also precipitate the obvious question, is there a meaningful difference between a threshold of 20 and $22 \mathrm{mmHg}$ in practical terms?

\section{Targets or thresholds?}

The latest BTF guidelines derive the ICP threshold recommendation from a single-center (Cambridge) retrospective study [6] evaluating autoregulation, ICP, and outcome. The study was never intended to define an ICP treatment threshold, instead reporting an association between a single summary ICP value (averaged over the entire monitoring period) and 6-month outcomes after TBI. Not unexpectedly, patients who died had a higher average ICP than survivors, consistent with previous studies $[7,8]$.

\footnotetext{
*Correspondence: nino.stocchetti@unimi.it

${ }^{1}$ Department of Physiopathology and Transplantation, Milan University, Milan, Italy

Full author information is available at the end of the article
}

For contrasting viewpoints, please go to https://doi.org/10.1007/s0013

4-018-5249-y and https://doi.org/10.1007/s00134-018-5264-z.

\section{实 Springer}


The association between ICP and outcome was tested using a repeated sequential chi-square analysis which identified a threshold of $22 \mathrm{mmHg}$ for mortality and $18.15 \mathrm{mmHg}$ for favorable outcome.

The direct association of ICP values with outcome categories is simplistic, as a multivariable approach would be preferable. Obviously the ICP behavior during the entire monitoring period reflects injury severity, evolving pathophysiology, and multiple active therapeutic interventions. In the Cambridge study, the data was indicative of the average ICP value in severe TBI who, despite adequate treatment, did not survive injury. Unfortunately, the ICP value of $22 \mathrm{mmHg}$ has been interpreted quite differently, and proposed as the threshold for starting therapy.

Though practically speaking, an ICP threshold of 22 instead of $20 \mathrm{mmHg}$ is unlikely to have an impact at the bedside, the BTF guidelines recommendation has created great potential for confusion.

\section{Do we need thresholds?}

The association of raised ICP with worse outcome is well proven [7, 9], but there is not clear-cut evidence blessing one ICP number as beneficial, and other numbers as "evil". This could lead to a nihilistic attitude, based on the "absence of evidence", while ICP requires careful monitoring and quick responses. To this purpose, a threshold may be useful.

Historically, intracranial hypertension has been defined as $20 \mathrm{mmHg}$, which represents twice the accepted normal ICP [10]. There are no strict reasons to prefer 20 or $25 \mathrm{mmHg}$, once it is clear that these figures work mainly as an alarm. Experienced clinicians know that some patients may tolerate a moderately raised ICP (so that a $25 \mathrm{mmHg}$ threshold could be accepted), while others cases may suffer tremendously, with brain herniation possibly occurring even at ICP values below $20 \mathrm{mmHg}$ $[10,11]$. The treating team should be alerted by this alarm and seriously consider what is causing the ICP rise.

\section{Do we need doctors for treating ICP?}

Being in favor of a threshold does not favor a simplistic therapy for normalizing a number. Once the ICP level becomes a problem, doctors start a complex, often rapid, sequence: the reliability of the ICP signal is verified, common causes of pathological increase ruled out (such as fever or coughing), the integrity of brain stem reflexes assessed, and the usefulness of an urgent $\mathrm{CT}$ scan considered. Treating clinicians then have a range of options from osmotic therapy to emergent neurosurgical intervention.

ICP monitoring is a window inside the skull that provides minimal but crucial information on pathological events that increase the intracranial content. The treating team has the duty of reacting to the ICP alarm, to identify what is wrong, and, possibly, to target treatment.

\section{Lessons learned}

The latest severe TBI guidelines have been published with the intent of updating previous editions with the most rigorous literature review. In the specific case of ICP threshold the update has resulted in a minimal, clinically insignificant change $(2 \mathrm{mmHg})$ supported by a single misinterpreted study. A better interaction between clinicians and methodologists could have avoided the confusion between an average ICP and a useful trigger for starting treatment.

Interestingly, the same guidelines correctly recommend that "A combination of ICP values and clinical and brain $\mathrm{CT}$ findings may be used to make management decisions". Unfortunately, this statement is graded as level III, as less grounded on evidence than the infamous $22 \mathrm{mmHg}$ information. In the end, the modern approach to TBI guideline development is impaired by adherence to rigid statistical methods without rational, practical input from decades of clinical experience.

Again, a better understanding of what truly matters in clinical practice could help readers in making informed choices in the management of intracranial hypertension.

\section{Author details \\ ${ }^{1}$ Department of Physiopathology and Transplantation, Milan University, Milan, Italy. ${ }^{2}$ Neuro ICU Fondazione IRCCS Cà Granda Ospedale Maggiore Policlinico, Via F Sforza, 35, 20122 Milan, Italy. ${ }^{3}$ Operative Unit of Anesthesia and Intensive Care, S. Martino Hospital, Belluno, Italy. ${ }^{4}$ University of Pittsburgh, Pittsburgh, USA.}

Received: 14 May 2018 Accepted: 26 May 2018

Published online: 5 July 2018

References

1. Cooper DJ, Rosenfeld JV, Murray L, Arabi YM, Davies AR, D'Urso P, Kossmann T, Ponsford J, Seppelt I, Reilly P, Wolfe R, the DECRA Trial Investigators and the Australian and New Zealand Intensive Care Society Clinical Trials Group (2011) Decompressive craniectomy in diffuse traumatic brain injury. N Engl J Med 364(16):1493-1502. https://doi.org/10.1056/NEJMo a1102077

2. Hutchinson PJ, Kolias AG, Timofeev IS, Corteen EA, Czosnyka M, Timothy J, Anderson I, Bulters DO, Belli A, Eynon CA, Wadley J, Mendelow AD, Mitchell PM, Wilson MH, Critchley G, Sahuquillo J, Unterberg A, Servadei F, Teasdale GM, Pickard JD, Menon DK, Murray GD, Kirkpatrick PJ, RESCUEicp Trial Collaborators (2016) Trial of decompressive craniectomy for traumatic intracranial hypertension. N Engl J Med 375:1119-1130. https://doi. org/10.1056/NEJMoa1605215

3. Cnossen MC, Huijben JA, van der Jagt M, Volovici V, van Essen T, Polinder S, Nelson D, Ercole A, Stocchetti N, Citerio G, Peul WC, Maas AIR, Menon D, Steyerberg EW, Lingsma HF, CENTER-TBI investigators (2017) Variation in monitoring and treatment policies for intracranial hypertension in traumatic brain injury: a survey in 66 neurotrauma centers participating in the CENTER-TBI study. Crit Care 21(1):233. https://doi.org/10.1186/s1305 4-017-1816-9 
4. Le Roux P, Menon DK, Citerio G, Vespa P, Bader MK, Brophy GM, Diringer MN, Stocchetti N, Videtta W, Armonda R, Badjatia N, Böesel J, Chesnut R, Chou S, Claassen J, Czosnyka M, De Georgia M, Figaji A, Fugate J, Helbok R, Horowitz D, Hutchinson P, Kumar M, McNett M, Miller C, Naidech A, Oddo M, Olson D, O'Phelan K, Provencio JJ, Puppo C, Riker R, Robertson C, Schmidt M, Taccone F (2014) Consensus summary statement of the International Multidisciplinary Consensus Conference on Multimodality Monitoring in Neurocritical Care: a statement for healthcare professionals from the Neurocritical Care Society and the European Society of Intensive Care Medicine. Intensive Care Med 40(9):1189-1209. https://doi. org/10.1007/s00134-014-3369-6

5. Carney N, Totten AM, O'Reilly C, Ullman JS, Hawryluk GWJ, Bell MJ, Bratton SL, Chesnut R, Harris OA, Kissoon N, Rubiano AM, Shutter L, Tasker RC Vavilala MS, Wilberger J, Wright DV, Ghajar J (2016) Guidelines for the management of severe traumatic brain injury, 4th edn. Brain Trauma Foundation, New York, pp 1-244

6. Sorrentino E, Diedler J, Kasprowicz M, Budohoski KP, Haubrich C, Smielewski P, Outtrim JG, Manktelow A, Hutchinson PJ, Pickard JD, Menon DK, Czosnyka M (2012) Critical thresholds for cerebrovascular reactivity after traumatic brain injury. Neurocrit Care 16(2):258-266. https://doi. org/10.1007/s12028-011-9630-8

7. Marmarou A, Anderson RL, Ward JD, Choi SC, Young HF, Eisenberg HM, Foulkes MA, Marshall LF, Jane JA (1991) Impact of ICP instability and hypotension on outcome in patients with severe head trauma. J Neurosurg 75:s59-s66

8. Stocchetti N, Colombo A, Ortolano F, Videtta W, Marchesi R, Longhi L, Zanier ER (2007) Time course of intracranial hypertension after traumatic brain injury. J Neurotrauma 24(8):1339-1346. https://doi.org/10.1089/ neu.2007.0300

9. Vik A, Nag T, Fredriksli OA, Skandsen T, Moen KG, Schirmer-Mikalsen K, Manley GT (2008) Relationship of "dose" of intracranial hypertension to outcome in severe traumatic brain injury. J Neurosurg 109(4):678-684. https://doi.org/10.3171/JNS/2008/109/10/0678

10. Stocchetti N, Maas AIR (2014) Traumatic intracranial hypertension. N Engl J Med 370:2121-2130. https://doi.org/10.1056/NEJMra1208708

11. Marshall LF, Barba D, Toole BM, Bowers SA (1983) The oval pupil: clinical significance and relationship to intracranial hypertension. J Neurosurg 58(4):566-568 